\title{
23
}

\section{Consequences of current organizational concepts on Management Control and Design / Production Processes interactions}

\author{
O. Sénéchal, D. Raviart, C. Tahon \\ L.A.M.I.H., Université de Valenciennes \\ Le Mont Houy BP 311, 59304 VALENCIENNES, \\ FRANCE \\ Tel: + 33327141354, Fax: +33327141288 \\ e-mail : senechal@univ-valenciennes.fr
}

\begin{abstract}
In this paper, we first discuss the role of accounting, according to the current organizational concepts like Concurrent Engineering, Target Costing, and Value Analysis. In this context, we define the notions of measurement, estimation and evaluation, and situate them in the design / production process. Then we show the necessity of performance indicators between accountants, designers and producers and we deduce a set of conditions that a pertinent performance evaluation system has to fulfill. After a short description of the activity concept in Activity Based Costing ( $A B C)$ and Activity Based Management ( $A B M)$, we introduce a modeling methodology based on this concept, and we describe the associated Decision Support System (DSS). This proposal constitutes, in a concurrent engineering context, a support for communication about past, current and future performances of the design / production process. It is based on a double modeling of the firm for simulation, and on the exploitation of the results with a multi-criteria approach, allowing a multi-disciplinary team to participate to the design phase. This global approach has been implemented in an industrial site and we discuss first results.
\end{abstract}

Keywords

Costing, organization, integration, $\mathrm{ABC}$, simulation. 


\section{INTRODUCTION}

Nowadays, the evolution from a mass-economy to an economy of variety and reactivity forces the firms to be innovative while searching for control of costs, lead times, and quality in a continuous manner. As a result, design and production methods have to change, and some organizational concepts based on transformation and project management appears. This context implies to reconsidering cost structures, the role of costs in decision processes, and more globally, the vision of the control activity of the firm.

\section{A POINT OF VIEW ON THE CONTROL OF THE ACTIVITY OF THE FIRM}

Current constraints have direct consequences on organizational methods as much for production management (Just-in-Time, Cost Kaizen and Total Quality Control) as for development or design (Design to Cost, Value Analysis, and Design for Manufacturing...). These methods and concepts are characterized by a research of transformation, most common principles being decentralization, cooperation with suppliers, diagnostics, anticipation and distribution of responsibility.

This tendency induces us to reconsider the information system of the firm, and particularly the cost management system. Management control, as a specific function, results from the transfer of systems analysis coming from biology, and of cybernetics coming from electronics, towards social sciences, (Mévellec, 1991). Effectively, the firm can be considered as a global regulated system that has to satisfy objectives (order) generally dictated by the market (in terms of variety, cost, quality and lead times). For this, solutions must be proposed (or designed) with regard to these objectives and to the real performance of the firm (that must be previously measured). The proposed solutions must be compared after estimating the corresponding performances. When a decision is made (a set of solutions is chosen), a command is given to the manufacturing process that provides products or services satisfying the needs expressed by the market. Then the obtained performances must be measured to allow, on the one hand, to verify that estimates are confirmed (and to make corrective decisions, if necessary), and on the other hand, to provide information for the design of future products or services.

This very simplified vision of the firm, illustrated by Figure 1, points up what can appear as the main role of control managers in firms being their contribution to measurement, estimation and comparison of performances for making good decisions. 


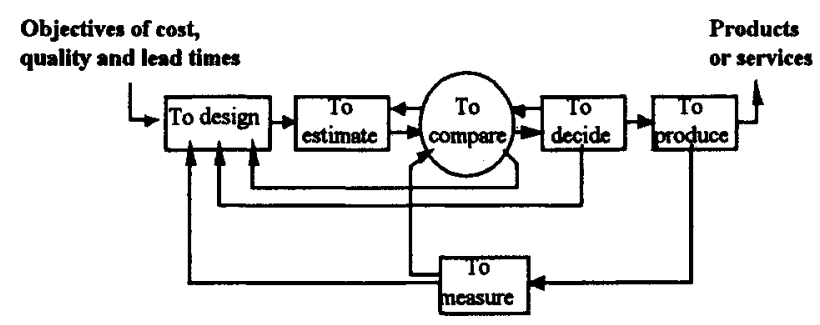

Figure 1. Cybernetic vision of control activity.

Some precautions must be taken about the implementation of the regulating notion. If the detection of unfavorable results must trigger corrective actions to achieve objectives, the detection of favorable results must not induce moderation on these efforts. On the contrary, the system must amplify the phenomena, to obtain continuous improvement of performances (Mévellec, 1991).

\section{CONSEQUENCES ON THE PERFORMANCE INDICATION METHODS AND TOOLS}

The previously introduced loop leads us to underline the consequences of growing cognitive and politic autonomy, that originates the transfer from a measurement problematic, to a diagnostic problematic, Lorino, 1996. Effectively, providing information on performance about given activities (in response to the question "how much?") is now useless without information on the reasons of these performances (response to the question "why?"). Where in the past, information had verification and repression finality; it must now be dedicated to the interpretation for action and apprenticeship. This reality induces that performance indication systems have to allow for cause-effect link comprehension.

Three consequences on the performance indication system can be found. First, it must be based on a model able to distinguish products (and their components), activities and resources. Each of these entities has effectively an impact on performances and can constitute the distinctive element of different tactical or operational choices. Second, indicators must be more economical and physical: the explanatory power of economical indicators is now recognized as not being sufficient to allow diagnostics, (Bescos and Mendoza, 1994), (Giard and Pellegrin, 1991), (Lorino, 1996). Finally, simulations must be performed due to the predictive significance given to the estimate notion.

In the first part of this paper, the role of the management controller in organizational structures that characterize current firms has been specified. These new decentralized organizations, where decision is distributed between several services and hierarchical levels, make even more pertinent the action of management controller, (Bescos and Mendoza, 1994). In a very global manner, the role of the management controller is to implement, in a concurrent approach; the regulating loop previously presented. 
This objective can be defined in the following sub objectives:

- to ensure the communication between people having different skills (translating problematic) and/or coming within different hierarchical levels (deployment or aggregation problematic);

- to provide information allowing us to know the relevance, the efficiency, and the effectiveness of activities that are (or that will be) implemented in the firm;

- to make reliable estimations about future activities, and for this, to have a realistic image of the sub-systems of the firm (physical, information, decision, organization and economic system).

All these conditions must be fulfilled to guide good decisions, to generate continuous improvement of manufacturing processes ("Kaizen" approach) and of development/design processes ("concurrent engineering" or "design to cost" approach).

Since the last ten years, numerous reflections have been carried out about accounting models or methods allowing to join these objectives. It seems from these reflections that modeling of the activities, through methods like Activity Based Costing ( $\mathrm{ABC}$ ) and Activity Based Management (ABM) are emerging and constitute a potential response to the presented problematic.

\section{ADVANTAGES OF ABC AND ABM}

Activity Based Costing as a method appeared in the eighties owing to the works of Robin Cooper and Robert Kaplan, (Cooper and Kaplan, 1991), authors of the current mechanisms of the method, and owing to Michael Porter, inventor of the Value Chain, (Porter, 1986). The CAM-I introduced the theoretical approaches of Porter, Cooper and Kaplan in a practical and formalized methodology, in the Cost Management System (CMS) project, (Berliner and Brimson, 1986), (Troxel, 1986), (Lorino, 1991). Then the Activity Based Management (ABM) appeared, where the concept of activity is used for strategic control of the firm, and where a real management by activities is driven, with the implementation of a coordination logic, an organizational engineering logic, and of a set of dashboards, (Lebas, 1994).

Regarding the reliability of information, approaches like $\mathrm{ABC}$ and $\mathrm{ABM}$ avoid artificial allocations. The first advantage of $A B C$ is that expenses of the firm are first assigned to a set of significant activities, using resource drivers. Resource drivers (for example, duration of an activity for assignation of wages) come from the information system of the firm (Computer Aided Manufacturing, internal invoicing, questioning...). Second, activity costs are assigned to cost objects (a cost object can be a product, or a component, a document, a service). This assignation is made with activity drivers, that are specific to each activity, and that allow quantifying the cost objects' consumption or demand for each activity. 
In terms of relevance of information, $A B C$ leads to a better understanding of the value creation and to a better cost mastering. The notion of activity favors a dynamic approach to decision making because it represents what the organization really does, (Bescos and Mendoza, 1994). To evaluate relevance and efficiency, what new management accounting has to do is: first to allow managers to know to what extend resources contribute to the value of the product, and second to allow each firm member to know what they can do to increase added value and to decrease cost. Activity Based Costing contributes to the vertical integration in providing operational performance indications, and in contributing to the identification of the key success factors of the company, and to strategic decision support.

A process is a set of activities linked by significant information or physical flows, and associated to provide a material or immaterial product. A process is so transversal in a functional, spatial and temporal point of view: it can need the participation of different skills in the firm (as for example, the process "improvement of quality"), use resources located everywhere in the firm (for example the process "to design and to implant information system") and be implemented in long term (as the process "to promote").

Following an approach based on the process analysis, each effort is made to optimize the global performance, (Lorino, 1996). Thus, if a process analysis is made in the previously quoted example, the first question will be "what are the costs and value added induced by the "data processing" process.

Concepts of activity and process seem to be theoretically relevant for a management controller to ensure his role of integration and decision support. Nevertheless, tools currently used to exploit these concepts are not quite adapted to the different data processing necessary for performance evaluation according to a tactical and operational point of view.

We propose so in the next part a methodology aiming to respond to these needs.

\section{PROPOSAL OF A MODELLING METHODOLOGY}

One of the basic principles of our modeling methodology is that an expense can only be determined when a given activity is performed by a given resource to obtain a given cost objective.

The second principle is that making decisions needs indication of performance on each of these categories. Designers need to know the production cost of a product with new features, which of these features influence costs, and to compare these costs to the corresponding added value for customers. Management has to know the profitability of resources, to make tactical decision on new investments, and operationals have to know the contribution of each of their activities to the global performance and, to feel implicated in the competition of the firm.

The main characteristic of our approach is the double modeling of the company, according to two further points of view, (Sénéchal, 1996): a top-down analysis of services and/or resources of the company, leaning on a representation of physical elements that implement these functions, and an analysis focused on the processes 
and not on their physical supports (resources). Successive refinements of the processes constituting "macro-activities" allow an analysis to be performed. The modeling of a firm according to this approach is shown in Figure 2

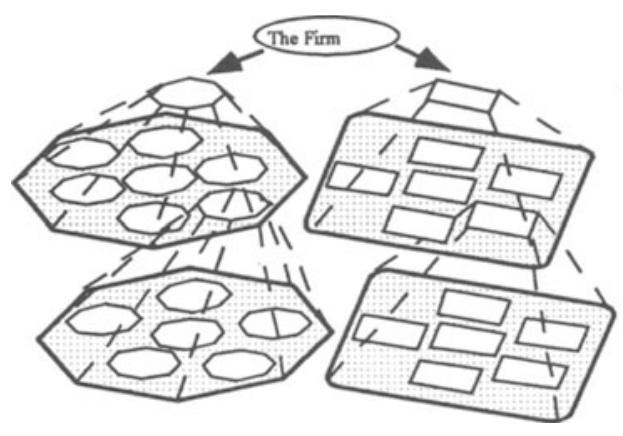

Figure 2 A double modeling of the firm.

The influence of entities going through activities and resources is double: entities are consumed by activities, and their cost can be part of the cost of these activities (for example, the cost of oil for preventive maintenance activities); they also can influence the behavior of processes, according to their role in activities. For modeling these entities as a whole, we use the notion of transformable entity, and define the role of each transformable entity towards activities in using the modeling method Extended SADT (Feller 1989). This method was adapted to our economical analysis requirements. On Figure 3, we show the model of an activity "to make plan" and of a transformable entity, which constitute the interface with environment.

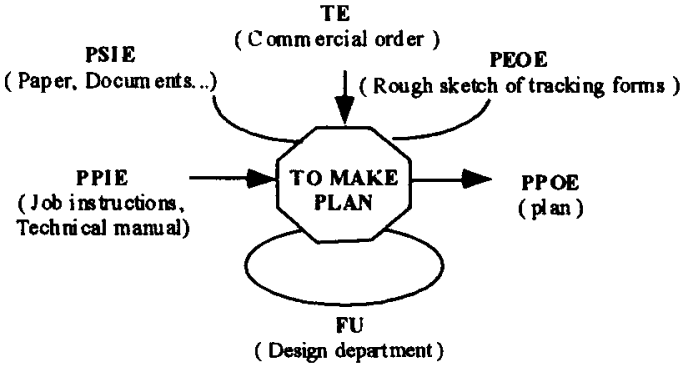

Figure 3 Modelling of an activity and its interfaces.

The different interfaces between the activity and its environment are entities having specific roles and implementing some specific notions:

- The Processing Purpose Input Entity (PPIE): it is the principal input, its value is modified throughout the activity.

- The Processing Support Input Entities (PSIE): they represent the entities 
necessary for the achievement of the activity, but they do not depend on the resource. These entities can be physical (e.g., some screws for an assembly activity) or informational (e.g., the assembly operation list).

- The Trigger Entities (TE): they correspond to the notion of trigger, they are entities necessary for the starting of the activity.

- The Processing Purpose Output Entity (PPOE): it is the main objective of the activity. It corresponds to the principal output, that is to say the entity whose value is modified. There is only one kind of PPEO for each activity, and it is common to each activity of the process.

- The Processing Effect Output Entities (PEOE): they represent the physical entities (waste, scraps...) and informational entities (resources release messages, trigger of other activities...) resulting from the performing of the activity. These entities are factors coming from the activity, and influencing activities of other processes.

- The resource notion is distinct from the input notion. It is a functional unit.

These models allow taking into account each element contributing to the costs and performances of the firm, as well as of their mutual interaction. Performances and costs are deduced from these simulations owing to notions stemming from automatic sciences.

\section{INDUSTRIAL APPLICATION}

The industrial site is a medium sized company (nearly 400 persons) producing ball and roller bearings, essentially from orders. Each product corresponds to a well identified customer, who waits for a precise technical and economic response to his needs. The principal added value is the technical know-how and the trade mastery. Production is made in little and middles series, products are various but with comparable technologies.

It is important to note that in the firm, the demand for concerning our project, came from the technical manager who expressed a need for tools, allowing designers to know the impact of their decisions on production costs, and more generally on performances. For the marketing manager, the need was about credibility and reliability of quotations. To make better products than competitors, he needed a means to distinguish products, and to identify for a given product its characteristics influencing the final production cost. For producers, the advantage was to be involved in the decision process of the firm, in giving some expectations on their future activities corresponding to the manufacturing of new product. The accounting manager saw in the project the opportunity to implement a performance evaluation system, allowing him to enrich his knowing of the operational processes of the firm. His interest was to be more implicated in the design and production processes, and to not "suffer" decisions in regarding costs of which he was not responsible.

The information for the members of the firm allowed presenting the objectives 
of the project, and the stakes of their participation. This task consisted in information and reflection meetings with the managers (technical, marketing, accounting...), and discussions with operational actors in their place of work, aiming to identify their activities and respective roles.

Grouping of activities in processes was made in analyzing flows existing in the firm (physical, information and decision flows). Models of processes have been validated by managers, and successive modifications obtained by consensus.

The different technical managers were quickly aware that this kind of cost approach might become a criterion for their decisions. The subjectivity part in decision making being reduced, the justification of choices with regard to the objectives of the firm were facilitated. For example, the choice was made for the investment in new equipment, for future products manufacturing, after consulting the information given by the estimation system (cost of set-up, of manufacturing, working factor.).

A dashboard composed of physical and/or economic performance indicators can be associated to each point of view, and adapted to users needs. The approach respects the cognitive autonomy of each in taking into account different points of view, and ensuring the evaluation coherence associated with a common model.

\section{CONCLUSION}

We have specified the principles that, according to us, must be applied to answer the current needs of engineers in term of performance evaluation. We made a proposal of performance estimation and evaluation approach, supported by a software environment. This approach does not assert to solve the problem on its own, but to contribute to some improvements. Its implementation being not totally completed, we can not give quantified and perpetuated results. Nevertheless, theoretical evaluation and partial practical results allow us to affirm its coherence with current industrial expectations, and to consider interesting perspectives.

\section{REFERENCES}

Berliner C., Brimson J. A. (1986) Cost management for today's advanced manufacturing ; the CAM-I conceptual design., HBS Press, Boston.

Bescos P.L., Mendoza C. (1994) Le management de la performance Editions compatibles Malesherbes, Paris.

Cooper R., Kaplan R.S. (1991) The Design of Cost Management Systems. Robert KAPLAN Consulting Editor, Edition Prentice Hall.

Feller A. \& Rucker R. (1989) Extending Structured Analysis Modelling with A.I.: An Application to MRPII Profiles and SFC Data Communications Requirements Specifications. IFIPS Conference Paper, November 1989.

Giard V., Pellegrin C. (1991) Fundaments de l'évaluation économique dans les modèles économiques de gestion, 3è congrès international de Génie Logiciel, 
Tours.

Lebas M. (1994) Du coût de revient au management par les activités. Revue Française de Comptabilité, 258, Juillet Août 1994.

Lorino P. (1991) Le contrôle de gestion stratégique. La gestion par les activités. Dunod, Paris.

Lorino P. (1996) Le pilotage de l'entreprise: de la mesure à l'interprétation, Cohérence, Pertinence et Evaluation, ECOSIP, Economica, Paris.

Mévellec P. (1991) Outils de gestion. La pertinence retrouvée. Editions Compatibles Malesherbes, Paris.

Porter M. (1986) L'avantage concurrentiel. inter Editions, Paris.

Sénéchal O. (1996) Proposition d'une méthodologie pour l'aide à l'estimation des performances physico-économiques des systèmes de production dans une approche concourante. Thèse de Doctorat, LAMIH - LGIL, Université de Valenciennes, 27 Février.

Troxel R. (1986) Performance Measurement, Actes du colloque CAM-I: Cost Management System Project - Phase 1 Conceptual Design, 8-9 Décembre Nice. 